Supporting Information for

\title{
Assembly and reassembly of polyelectrolyte complex formed by poly(ethylene glycol)-block-poly(glutamate sodium) and $S_{5} R_{4}$ peptide
}
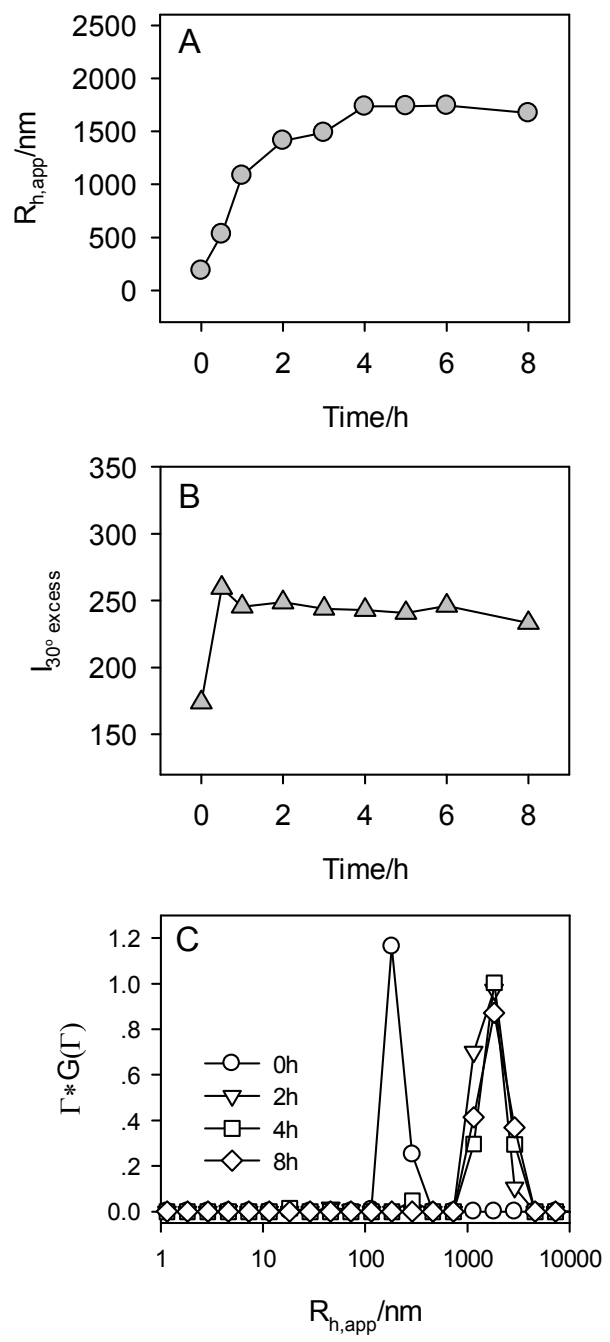

Figure S1. Time dependence of the $R_{\mathrm{h}, \text { app }}(\mathrm{A})$, excess scattered intensity (B), and size distribution (C) (scattering angle: $30^{\circ}$ ) of the assemblies formed by $\mathrm{PEG}_{114}-\mathrm{PGlu}_{64}$ and $\mathrm{S}_{5} \mathrm{R}_{4}$ at $+/-=5.0$ in deionized water. 


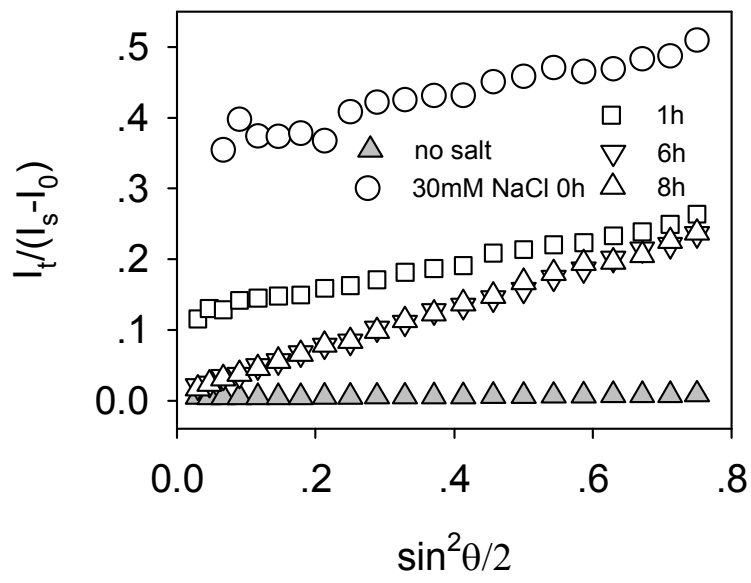

Figure S2. Angular dependence of the excess scattered intensity of the $\mathrm{PEG}_{114}-\mathrm{PGlu}_{64} / \mathrm{S}_{5} \mathrm{R}_{4}$ assemblies at $+/-=1.0$ before and after the addition of $30 \mathrm{mM}$ $\mathrm{NaCl}$. 

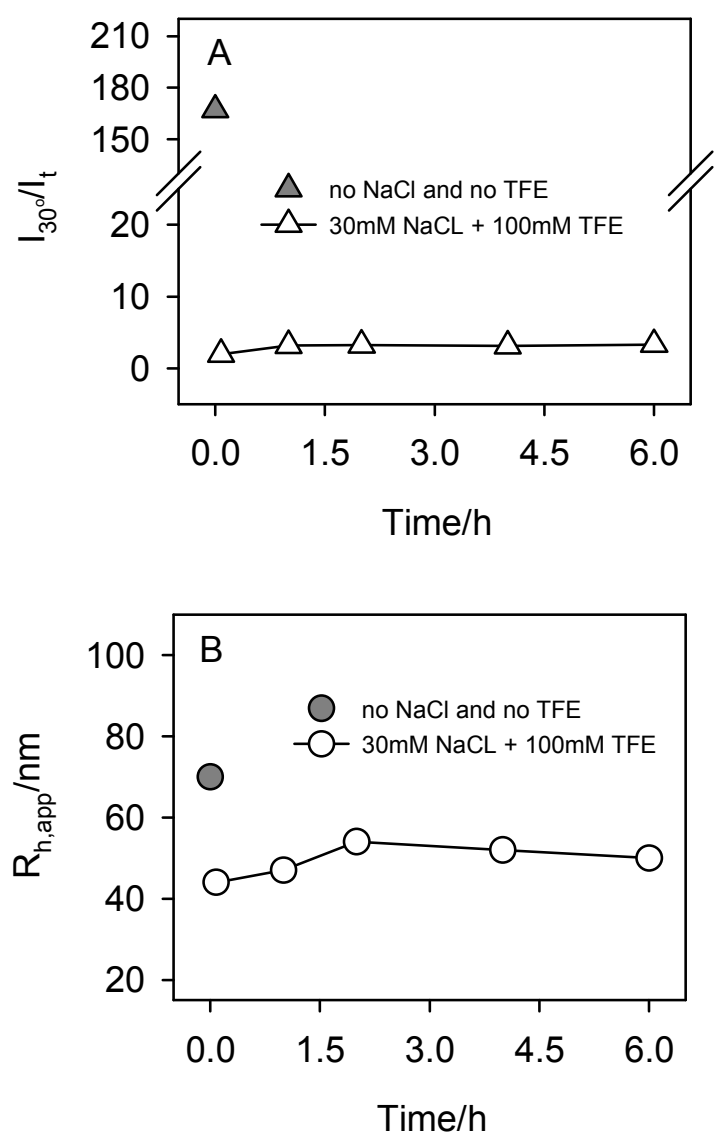

Figure S3. Time dependence of the excess scattering intensity (A) and the hydrodynamic radius (scattering angle: $30^{\circ}$ ) of the $\mathrm{PEG}_{114}-\mathrm{PGlu}_{64} / \mathrm{S}_{5} \mathrm{R}_{4}$ assemblies at $+/-=1.0$ with or without $100 \mathrm{mM} \mathrm{TFE}$ and $30 \mathrm{mM} \mathrm{NaCl}$ 


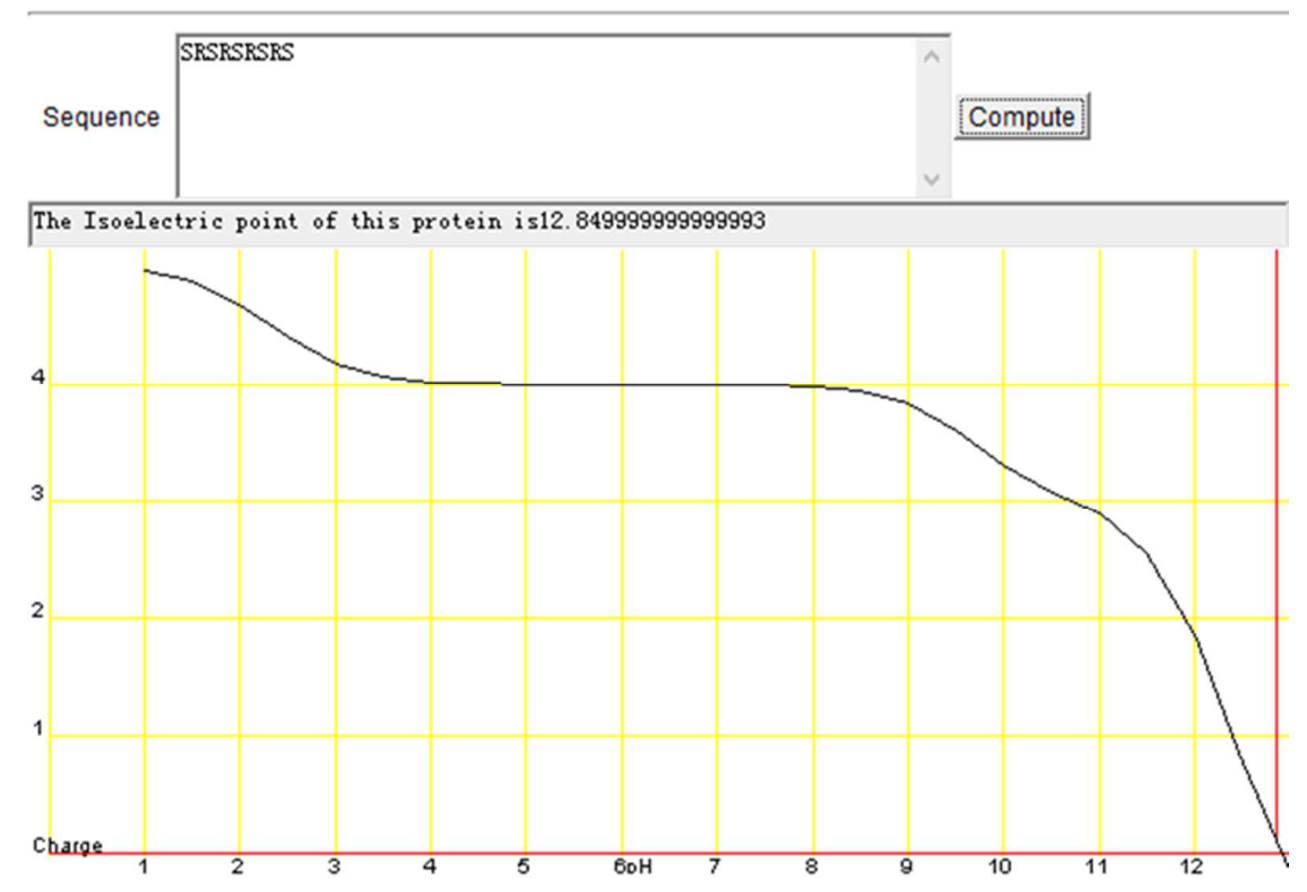

Figure S4. $\mathrm{pH}$ dependence of the effective charge on $\mathrm{S}_{5} \mathrm{R}_{4}$. The data were calculated by JaMBW 1.1 software (http://www.bioinformatics.org/JaMBW//) 

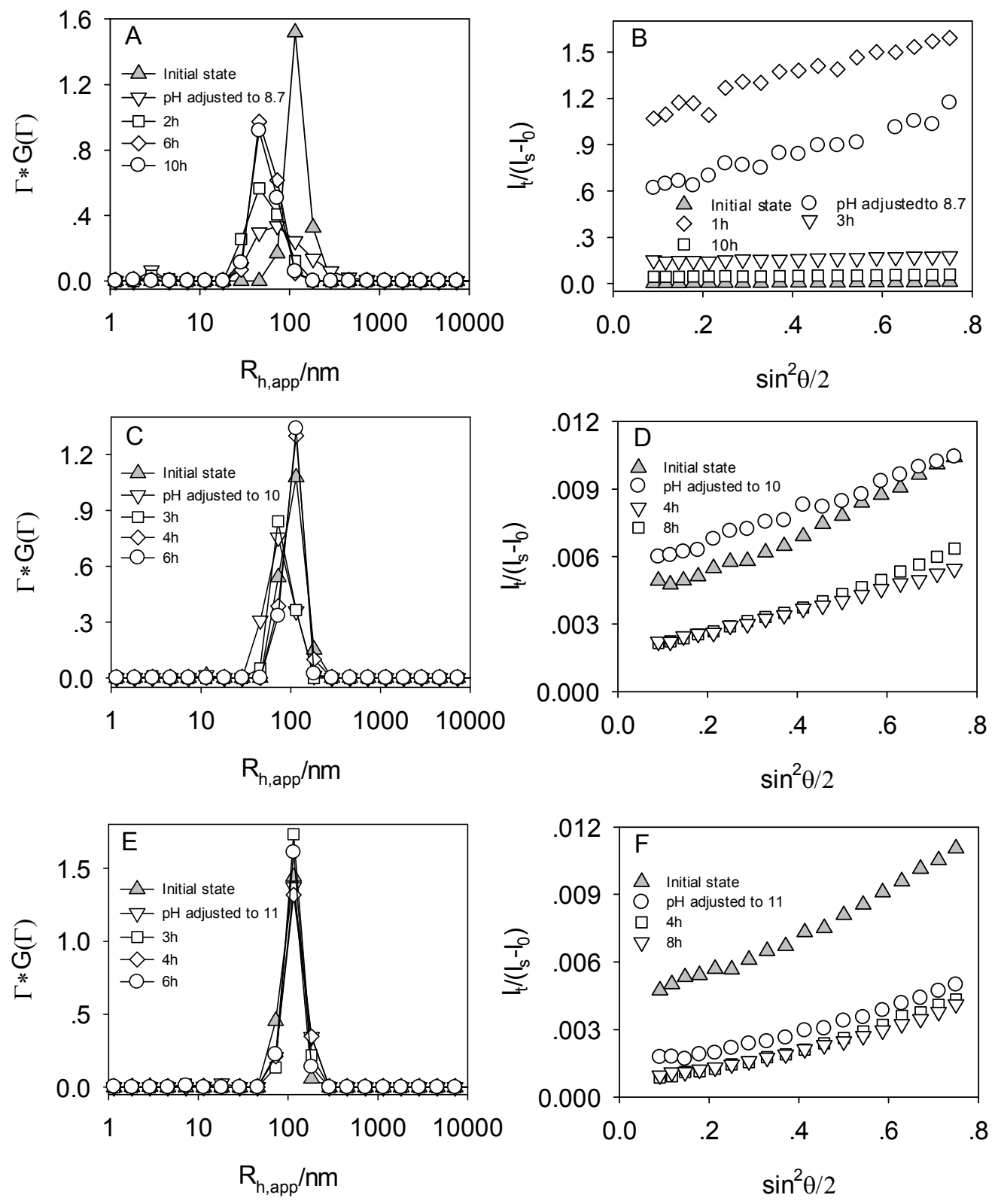

Figure S5. The hydrodynamic radius distribution (A, C, E) (scattering angle: $30^{\circ}$ ) and the angular dependence of the excess scattered intensity (B, D, F) of the $\mathrm{PEG}_{114}-\mathrm{PGlu}_{64} / \mathrm{S}_{5} \mathrm{R}_{4}$ assemblies at $+/-=1.0$ before and after changing the solution $\mathrm{pH}$ to $8.7(\mathrm{~A}, \mathrm{~B}), 10(\mathrm{C}, \mathrm{D})$, and $11(\mathrm{E}, \mathrm{D})$. 

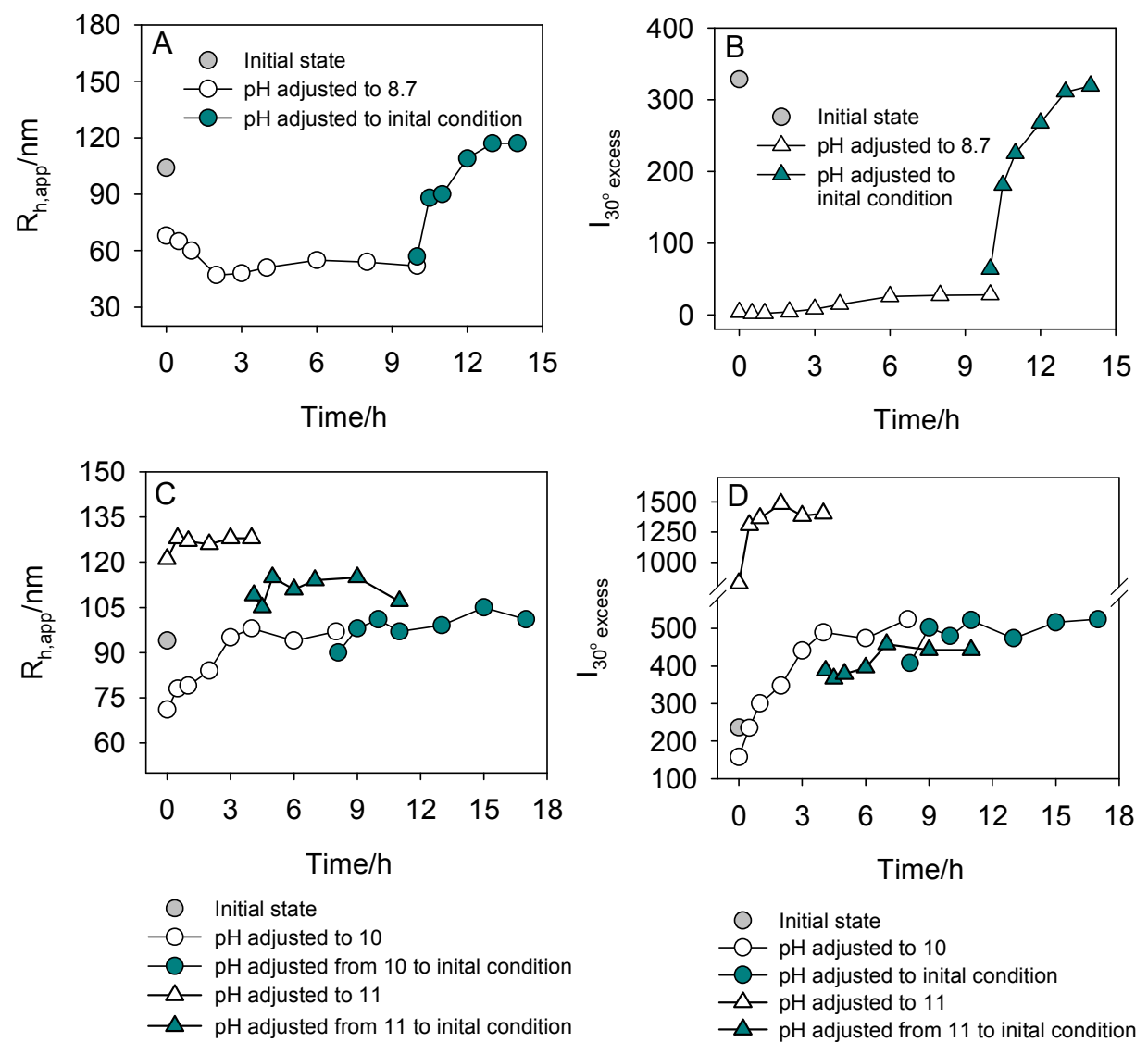

Initial state

$-\mathrm{O}-\mathrm{pH}$ adjusted to 10

- $\mathrm{pH}$ adjusted to inital condition

$\triangle \mathrm{pH}$ adjusted to 11

$\triangle \mathrm{pH}$ adjusted from 11 to inital condition

Figure S6. Time dependence of the $R_{h, a p p}(A$ and $C$ ), and the excess scattered intensity ( $\mathrm{B}$ and $\mathrm{D}$ ) of $\mathrm{PEG}_{114}-\mathrm{PGlu}_{64} / \mathrm{S}_{5} \mathrm{R}_{4}$ assemblies at $+/-=1.0$ before and after changing the solution $\mathrm{pH}$ to $8.7,10$, and 11 , separately, as well as restoring $\mathrm{pH}$ to initial conditions ( $\mathrm{pH} 7.1$, indicated by the dark green solid symbols) . 